\title{
Effect of organizational climate upon the job performance of instructors' physical education
}

\author{
Luqman M.S. ${ }^{\mathrm{ABCDE}}$, Rehman J.U. ${ }^{\mathrm{ACD}}$, Islam Z.U. ${ }^{\mathrm{ABD}}$, Khan S.D. ${ }^{\mathrm{CD}}$ \\ Department of Sports Sciences and Physical Education Gomal University D.I. Khan, Pakistan
}

Authors' Contribution: A - Study design; B - Data collection; C - Statistical analysis; D - Manuscript preparation; E - Funds collection

\begin{abstract}
Purpose:

The current study was conducted to examine the effect of organizational climate on the Job Performance of Instructors' Physical Education.

Material: $\quad$ A quantitative method was employed for this purpose; a survey research design was used. There was 169 Instructors' Physical Education preferred through stratified sampling technique. A structured questionnaire was administered to collect the data. The data was analyzed using inferential statistics (linear and multiple regression).

Results: $\quad$ The results of the study indicated that organizational climate affect job satisfaction significantly. All the dimensions of organizational climate contribute to increasing the Instructors' Physical Education performance.

Conclusions: $\quad$ The current study concluded that Instructors' Physical Education not only feel comfortable in a healthy organizational climate but also increase their level of performance. The study also depicted that effective communication structure, reward system, teamwork, career development, and effective planning and decision making strategies are the valuable ingredients to enhance the performance of Instructors' Physical Education. Keeping in view the results of the current study, it is recommended that head of the institution may focus or promote supportive culture in their respective educational institutions to enhance the performance of instructors' physical education.

Keywords: $\quad$ organizational climate, job performance, instructor, physical education.
\end{abstract}

\section{Introduction}

The ultimate development and survival of an organization depend upon the competency of the employees in today's competitive environment. The required knowledge, skills, and behavior are essential for an organization to reaching its goals. Jing et al. [1] stated that only those employees concentrate on their tasks, demonstrate creativity and committed who feel comfortable in the environment of an organization. The high expectations from the employees are linked with a suitable environment in the organization. School is like an organization in which different people having different positions working in the same conditions to achieve the desired objectives. Organization Climate (OC) is essential among all these conditions since OC includes many dimensions associated with School. According to Lazaridou and Tsolakidis [2] organizational climate refers to the environment in which employees perform their tasks in the working environment. The present study aimed to examine the effect of OC upon the JP of IPEs of KP.

Organizational climate: According to Ali and Patnaik [3] there are various popular subjects for research and organizational climate is one of them. Research is very useful in this field if it would be conducted in the field of education. The organization has a great role in the development of society and the well-being of the people in an organization, different people have a different role, and some have a more important role as compared to other people who are working with them. But every person has

() Luqman M.S., Rehman J.U., Islam Z.U., Khan S.D., 2020

doi:10.15561/26649837.2020.0204 their own particular role in the organization. So, every individual plays a vital role to run the organization. Individuals who are working in an organization can be evaluated according to their assigned responsibilities. While evaluation, several factors could be involved. Such factors involve resources, the structure of the organization, rule and regulation, reward structure, the role of the leadership, hinders whether hob is satisfied or not and conflict management.

DeConick [4] states that organizational climate as members of the organization perceived it and describe its feature according to their climate. In any organization, leadership has a vital role and a leader can change the climate of an organization. Chen and Hung [5] expressed that various factors have their own role and influence the organizational climate. There are several elements in the organizational climate such as control autonomy, reward, respect, and procedure and role expectation. Such elements contribute a significant role in any organizational climate. According to De Conick [4] organizational climate plays an important role in the learning process. The congenial atmosphere has definitely in any educational environment and it could be effective in the learning process. It is the responsibility of the School manager to provide opportunities to the teachers to develop their hidden abilities. According to human resources, structure and symbolic frames have essential organizations and managers should concentrate on such frames in order to achieve organizational goals. Attkinson and Frechette [6] refer to organizational climate as a set of characteristics specific to the organization that may be 
made from the organization, treatment with the employees and its atmosphere.

Job Performance: According to Griffin [7] the term job performance may be defined as an act of completing the given task. Oxford Dictionary [8] spells out the meaning of Performance is to carry out fulfil the task. Raza and Shah (2010) associate performance with the outcome. If the teacher achieved the desired outcome then performance would be up to the mark. According to Oguntimehin Kuewumi and Adeyemi [9] Teacher job Performance referred to as responsibilities performed by a teacher in a specific time limit in the school environment to accomplish the school objectives. According to Griffin [7] there are different indicators to measure the job performance of teachers (IPEs) include subject matter knowledge, instructional planning, and management, communication and assessment skills. The teacher role is important and crucial in the teaching-learning process. Different strategies used by a teacher while transmitting the knowledge to his students. A good teacher always uses strategies that are more suitable and fruitful for the purpose of obtained school objectives. According to Zia-Ul-Islam and Khan [10] a teacher's way of questioning, instructions, directions, explanation, and attitude towards his profession play a significant role in achieving classroom objectives. According to Balkar [11] every student has own mental capability level of understanding. Besides this, there exist individual differences among the students, so it is the responsibility of the teacher to comprehend each student so that learning objectives could be achieved. So the teacher role is not less important in school. If the teacher is equipped with the required skills then the school objective can be easy to achieve. According to Gera and Beri [12] if the teacher's satisfaction level is high then he is more committed to his profession and it might increase the performance. Theory $\mathrm{X}$ and $\mathrm{Y}$ developed by McGregor in 1960. Oguntimehin Kuewumi and Adeyemi [9] argue that according to theory $\mathrm{X}$, negative characteristics cause low performance while theory $\mathrm{Y}$ hypothesized the positive characteristics cause high performance. According to Balkar [11] there are some reasons which cause low performance in any organization includes low salary, lack of career opportunities, and lack of reward system, poor facilities, role ambiguity and behavior of a leader. The main focus of this study is organizational climate which is one of the factors which has an effect on job performance. The following two null hypotheses are generated associated with objectives: -

Hypotheses: There is no significant effect of
Organizational Climate (OC) upon Job Performance (JP) of IPE; there is no significant effect of Ten (10) dimensions OC upon JP of IPEs

Objectives: To examine the effect of OC upon the JP of IPEs of KP, to investigate the Ten (10) dimensions of OC on the IPEs' Job Performance.

\section{Materials and Method}

Population and Sample: There are 294 Instructors of Physical Education (IPEs) working in Government Higher Secondary Schools in Khyber Pakhtunkhwa was constituted population (Education Management Information system [EMIS], 13). A sample of 169 IPEs was chosen as a sample by using the Stratified probability sampling method. The strata were based on gender. Yamane [14] formula was used for the sample selection.

$$
\mathrm{n}=\mathrm{N} /\left(1+\mathrm{Ne}^{2}\right]=294 /\left(1+294 * 0.05^{2}\right)=16
$$

Design: The positivist approach was used while conducting this research. The result of the study is drawn through statistical analysis and then the conclusion was made. Additionally, the deductive approach was employed because it is based on the belief that the world is an observable phenomenon of different things processes and actions that work coherent and in a controlled way [15]. Based on the positivist approach, a Survey research design was applied. According to Kothari [16] survey research design is the process of collection of information from the sample individuals about some phenomenon by the response.

Instrumentation: An adapted questionnaire was used for data collection. The organizational climate scale was adapted from the instrument developed by Furnham and Goodstein [17] while Job performance scale was adapted from the tool developed by Atta [18].

Validity and Reliability: Validity and reliability are two important phases in instrument development. The validation of content validity was done through experts. For this purpose, content validity Ration (CVR) was used. The accepted criteria for each statement are ranging 0.31 [19]. The formula is given, $C V R=[(E-(N / 2) /(N / 2)] E$ denote to relevant item and $\mathrm{N}$ denote to total expert.

Statistical Analysis. The Table 2 indicates that all the items fulfil the criteria for retaining in the final instrument. The reliability of the questionnaire is measured by using Cronbach's Alpha. The table 3 shows the reliability score of the questionnaire.

Table 1. Showing sample size

\begin{tabular}{lllll}
\hline Respondents & Gender & Population & Percentage & Required sample \\
\hline \multirow{2}{*}{ IPEs } & Male & 186 & $63 \%$ & $169 * 63 \%=106$ \\
& Female & 108 & $37 \%$ & $169 * 37 \%=63$ \\
Total & ---- & 294 & 100 & 169 \\
\hline
\end{tabular}




\section{Results}

Table 4 indicates the Correlation analysis matric between the Ten (10) dimensions of OC and Job Performance. The table indicates that Positive correlation between the different dimensions of OC and Job Performance of IPEs. The table shows that there is a week correlation between Role clarity and Job Performance $\left(\mathrm{r}=.316^{* *}\right)$, Reward and Job Performance $(\mathrm{r}=.322 * *)$ Communication and Job Performance $\left(\mathrm{r}=.322^{* *}\right)$ and
Conflict and Job Performance $(\mathrm{r}=.294 * *)$.

The table 5 shows the regression output regarding the effect of OC upon JP of IPEs. The table reveals that $\mathrm{R}^{2}=.429$ indicates that $42 \%$ of the variance in IPEs job performance predicted by the organizational climate. The Beta value (.41) indicates that if there is one-unit increase in the independent variable then .41 unit increases in the dependent variable (JP). The F- value is 14.19 with $\mathrm{P}=.000<.05$ which provides strong evidence to reject the

Table 2. Showing Content Validity Ratio (CVR)

\begin{tabular}{lll}
\hline Scale & No. of Item & CVR Score \\
\hline OC & 44 & $0.3-0.8$ \\
JP & 39 & $0.6-0.8$ \\
\hline
\end{tabular}

Table 3. Showing reliability score of the instrument

\begin{tabular}{lll}
\hline Scale & No. of Item & Cronbach' Alpha Score \\
\hline OC & 44 & .847 \\
JP & 39 & .819 \\
\hline
\end{tabular}

Table 4. Correlation Analysis Matric of Organizational Climate and Job performance

\begin{tabular}{|c|c|c|c|c|c|c|c|c|c|c|c|}
\hline & RC & Rspt & Com & Rwd & $C D$ & PDM & Inv & TW & QS & CM & JP \\
\hline $\mathrm{RC}$ & 1 & & & & & & & & & & \\
\hline Rspt & $.567 * *$ & 1 & & & & & & & & & \\
\hline Com & $.529 * *$ & $.762^{* *}$ & 1 & & & & & & & & \\
\hline Rwd & $.359 * *$ & $.575^{* *}$ & $.682^{* *}$ & 1 & & & & & & & \\
\hline$C D$ & $.376^{* *}$ & $.356^{* *}$ & $.535^{* *}$ & $.570^{* *}$ & 1 & & & & & & \\
\hline PDM & $.413^{* *}$ & $.551^{* *}$ & $.742^{* *}$ & $.627^{* *}$ & $.630^{* *}$ & 1 & & & & & \\
\hline Inv & $.372 * *$ & $.504^{* *}$ & $.723^{* *}$ & $.453^{* *}$ & $.689^{* *}$ & $.588^{* *}$ & 1 & & & & \\
\hline TW & $.497 * *$ & $.513^{* *}$ & $.688^{* *}$ & $.530^{* *}$ & $.655^{* *}$ & $.536^{* *}$ & $.708^{* *}$ & 1 & & & \\
\hline QS & $.529 * *$ & $.605^{* *}$ & $.668^{* *}$ & $.541^{* *}$ & $.407^{* *}$ & $.483^{* *}$ & $.586^{* *}$ & $.580^{* *}$ & 1 & & \\
\hline CM & $.492 * *$ & $.560^{* *}$ & $.595^{* *}$ & $.499^{* *}$ & $.259^{* *}$ & $.183^{* *}$ & $.210^{* *}$ & $.378^{* *}$ & $.391^{* *}$ & 1 & \\
\hline$J P$ & $.316^{* *}$ & $.575^{* *}$ & $.322 * *$ & $.289 * *$ & $.449 * *$ & $.759 * *$ & $.682 * *$ & $.510 * *$ & $.778 * *$ & $294 * *$ & 1 \\
\hline
\end{tabular}

$R C=$ Role Clarity, Rspt=Respect, $C D=$ Career Development, PDM=Planning \& Decision Making, Inv=Innovation, $Q S=$ Quality Service, $C M=$ Conflict Management, $J P=J o b$ Performance

Table 5. Regression model regarding effect of Organizational Climate upon Job Performance

\begin{tabular}{|c|c|c|c|c|c|c|c|}
\hline & & & Unstar & coefficients & $\begin{array}{l}\text { Standardized } \\
\text { Co-efficient }\end{array}$ & & \\
\hline Model & $\mathrm{R}$ & $\mathrm{R}^{2}$ & B & Std. Error & Beta & $\mathrm{F}$ & Sig \\
\hline Constant & & & 3.068 & .381 & 8.647 & \multirow{2}{*}{14.19} & .000 \\
\hline $\mathrm{OC}$ & .510 & .429 & .390 & .094 & .510 & & .000 \\
\hline
\end{tabular}

Dependent variable: JP

Table 6. Multiple Regression regarding Impact of Ten (10) dimensions of OC on the JP

\begin{tabular}{lllllll}
\hline Model & R & R Square & $\begin{array}{l}\text { Adjusted R } \\
\text { Square }\end{array}$ & F- value & Sig & $\begin{array}{l}\text { Durbin-Watson } \\
\text { (DW) }\end{array}$ \\
\hline 1 & .581 & .492 & .317 & 8.67 & .009 & 1.42 \\
\hline
\end{tabular}

Dependent Variable: JP 
Table 7. Co-efficient

\begin{tabular}{|c|c|c|c|c|c|c|c|}
\hline \multirow[t]{2}{*}{ Model } & \multicolumn{2}{|c|}{$\begin{array}{l}\text { Unstandardized } \\
\text { Coefficient }\end{array}$} & \multirow{2}{*}{$\begin{array}{l}\text { Standardized } \\
\text { Coefficient } \\
\text { B }\end{array}$} & \multirow[t]{2}{*}{$\mathbf{t}$} & \multirow[t]{2}{*}{ Sig } & \multicolumn{2}{|c|}{ Collinearity Statistics } \\
\hline & B & Std.Error & & & & VIF & Tolerance \\
\hline (Constant) & 3.014 & .653 & & 4.616 & .000 & & \\
\hline $\mathrm{RC}$ & .312 & .181 & .612 & .069 & .945 & .412 & 2.424 \\
\hline Respect & .278 & .177 & .218 & 1.233 & .223 & .245 & 4.077 \\
\hline Communication & .273 & .156 & .140 & .257 & .798 & .156 & 6.404 \\
\hline Rewardsystem & .173 & .102 & .343 & .415 & .680 & .404 & 2.474 \\
\hline CD & .207 & .116 & . 113 & .974 & .334 & .276 & 3.623 \\
\hline PIngDmaking & .369 & .169 & .226 & 1.340 & .186 & .165 & 6.070 \\
\hline Innovation & .282 & .112 & .244 & .393 & .696 & .284 & 3.523 \\
\hline Teamwork & .188 & .137 & .132 & -.966 & .339 & .329 & 3.036 \\
\hline Qservice & .380 & .124 & .245 & .366 & .716 & .264 & 3.784 \\
\hline CManagment & .195 & .119 & .163 & .530 & .599 & .392 & 2.549 \\
\hline
\end{tabular}

null hypothesis. Thus null research hypothesis (H01) is rejected.

The table 6 indicates the impact of Ten (10) dimensions of OC on Job Performance. The table reveals that $\mathrm{R}^{2}=.492$ indicates that $49 \%$ of the variance in IPEs job performance predicted by different dimensions of organizational climate. The F- value is 14.19 with $\mathrm{P}=.009<.05$ which provides strong evidence to reject the null hypothesis. Thus second null hypothesis (H02) is rejected. The value of Durbin Watson (1.42) shows that there is no autocorrelation issue in data.

The table 7 shows the regression coefficient of predictor variables of dimensions of $\mathrm{OC}$ and Predicted JS. The result indicates that beta $(\beta)$, standardized coefficient regression of each predictor generated some degree of contribution in predicted (JS). The variation in JP associated with a given change in Role clarity $(\beta$ $=.612)$, respect $(\beta=.218)$, Communication $(\beta=.140)$, reward system $(\beta=.343)$, Career development $(\beta=.113)$, Planning and Decision making $(\beta=.226)$, Innovation $(\beta=$ $.244)$, Teamwork and support $(\beta=132)$, Quality service $(\beta=.245)$ and Conflict Management $(\beta=.163)$. The table also indicates the multicollinearity statistic which is one of the basic assumptions while using multiple regression analysis. The multicollinearity issue can be detected through the Variance Inflation Factor (VIF) and Tolerance. All the values fall in an acceptable range, so there is no issue of multicollinearity in independent variables.

\section{Discussion}

Organizational Climate is considered is one of the prime factors which directly or indirectly affect the performance of Instructors of Physical Instructors (IPEs). The basic purpose behind the study was to investigate the effect of Organizational climate upon the Job performance of IPEs working in Khyber Pakhtunkhwa. The result of the study shows that there is a significant relationship between different dimensions of $\mathrm{OC}$ and Job Performance. Week correlation was found between Respect and Job Performance, Communication and Job Performance and Conflict and Job Performance. The same result was mentioned by Adeyemi [9] He found that less importance given to effective communication channels,
Reward system and role clarity in the organization. School is an organization and teachers working without any reward negatively influence the performance of IPEs. The result of the study depicts that the effect of $\mathrm{OC}$ on Job Performance is significant. The result of the study is in line with Balkar [11] and Salemat, Samsu and Kamalu [20]. They found that a conducive organizational climate plays a crucial role in the Performance of IPEs. The work behavior of the IPEs is improved through a supportive organizational climate. The result of the study is consistent with Jing, Avery, and Bergsteiner [1]. They found that the performance of the IPEs is improved by providing necessary resources and supportive climate since the working conditions of the organization they require physically and psychologically is presented in a proper manner.

\section{Conclusion}

The study concluded that IPEs feel comfortable in a healthy organizational climate and cause an increase in performance. Effective communication structure, reward system, teamwork, career development, and effective planning and decision making strategies are implemented in the schools which enhance the performance of the teachers.

\section{Recommendations:}

The result of the study shows that Organizational Climate has a significant impact on the IPEs' Job Performance. Thus, it is recommended that the Principal may create a supportive climate in the school in order to enhance the IPE performance. For this purpose, School principal may lead from the front and build teamwork in the school to achieve short and long term goals. This may increase the level of satisfaction and a sense of belongingness to the organization. Government of Elementary and Secondary Education Khyber Pakhtunkhwa may conduct a workshop to train School Heads by hiring renowned trainers and scholars.

\section{Conflict of interest}

The authors declare that there is no conflict of interests. 


\section{Reference}

1. Jing FF, Avery GC, Bergsteiner H. Enhancing performance in small professional firms through vision communication and sharing. Asia Pacific Journal of Management. 2014;31(2):599- 620. https://doi.org/10.1007/s10490-013-9345-9

2. Lazridou A, Tsolakidis I. An exploration of organizational climate in Greek high schools. Academic Leadership: The Online Journal. 2011;9(1):8-16.

3. Ali A, Patnaik B. Influence of organizational climate and organizational culture on managerial effectiveness: An inquisitive study. The Carrington Rand Journal of Social Sciences. 2014;1(2):1-20.

4. DeConinck JB. The effects of ethical climate on organizational identification, supervisory trust, and turnover among salespeople.JournalofBusiness Research.2011;64(6):617-24. https://doi.org/10.1016/j.jbusres.2010.06.014

5. Chen C-J, Huang J-W. How organizational climate and structure affect knowledge management-The social interaction perspective. International Journal of Information Management, 2007;27:104-18. https://doi.org/10.1016/j.ijinfomgt.2006.11.001

6. Atkinson T, Frechette H. Creating a positive organizational climate in a negative economic one. Improving Organizational Climate to Transform Performance. InForum transforming performance. 2009. P. 1-3.

7. Griffin RW, Moorhead G. Organizational behavior. Nelson Education; 2011.

8. Speake J, editor. Oxford Dictionary of Proverbs. Oxford University Press; 2015. https://doi.org/10.1093/acref/9780198734901.001.0001

9. Oguntimehin YA, Kuewumi OA, Adeyemi M. Assessment of influence of quality assurance indices on secondary schools teachers'job performance. Bulgarian Journal of Science and Education Policy. 2018;12(1):123-39.

10.Zia-Ul-Islam S, Khan S. Influence of law and Order Situation upon University Sports, A Comparative Study of Public and Private Sector Universities of Khyber Pukhtunkhwa
(KP) Pakistan. Journal of Social Sciences \& Humanities, 2018;26(2):34-40.

11.Balkar B. The Relationships between Organizational Climate, Innovative Behavior and Job Performance of Teachers. IOJES, 2015. https://doi.org/10.15345/iojes.2015.02.007

12.Gera J, Beri N. Role Efficacy of Secondary School Principals In Relation to Professional Competency And Organizational Climate. Lovely Professional University; 2016.

13.Education Management Information system [EMIS]. Annual Statistical Report. 2018. [cited 2019 May 29]. Available from: https://www.kpese.gov.pk

14. Yamane H. Some trigonometric integrals and the Fourier transform of a spherically symmetric exponential function. arXiv preprint arXiv, 2018;1812.11730

15.Tashakkori A, Teddlie C. SAGE Handbook of Mixed Methods in Social \& Behavioral Research. 2455 Teller Road, Thousand Oaks California 91320 United States: SAGE Publications, Inc.; 2010. https://doi.org/10.4135/9781506335193

16.Kothari CR. Research Methodology (2nd ed ). New Delhi K.K. Gupta for New age International (P) Ltd; 2003.

17.Furnham A, Goodstein LD. The organizational climate questionnaire (OCQ). Annual-San Diego-Pfeiffer and Company. 1997;2:163-182.

18.Atta M. Gender based comparative study on the performance of subject specialists in southern districts of Khyber Pakhtunkhwa. [PhD Thesis]. Gomal University, D.I.Khan; 2012.

19.Lindell MK, Brandt CJ. Assessing interrater agreement on the job relevance of a test: A comparison of CVI, T, $\operatorname{rWG}(\mathrm{J})\}$, and $\left.\mathrm{r}^{*} \mathrm{WG}(\mathrm{J})\right\}$ indexes. Journal of Applied Psychology, 1999;84:640-7.. https://doi.org/10.1037/0021-9010.84.4.640

20.Selamat N, Samsu NZ, Kamalu NSM. The impact of organizational climate on teachers' job performance. EREJ, 2013;2:71-82. https://doi.org/10.5838/erej.2013.21.06

\section{Information about the authors:}

Luqman M.S.; http://orcid.org/0000-0003-1664-6351; Safdarkhan821@gmail.com; Department of Sports Sciences and Physical Education, Gomal University D.I. Khan; Gomal, Pakistan.

Rehman J.U.; http://orcid.org/0000-0001-8920-8884; jrbaloch@gmail.com; Department of Sports Sciences and Physical Education, Gomal University D.I. Khan; Gomal, Pakistan.

Islam Z.U.; (Corresponding author); http://orcid.org/0000-0003-2294-9447; ziaulislamgr8@gmail.com; Department of Sports Sciences and Physical Education, Gomal University D.I. Khan; Gomal, Pakistan.

Khan S.D.; http://orcid.org/0000-0002-7784-7678; drsalahuddinkhan@yahoo.com; Department of Sports Sciences and Physical Education, Gomal University D.I. Khan; Gomal, Pakistan.

Duz S.; Associate Professor; http://orcid.org/0000-0001-7611-4838; serkan.duz@inonu.edu.tr; Faculty of Sport Sciences, Inonu University; Malatya, Turkey.

Cite this article as:

Luqman MS, Rehman JU, Islam ZU, Khan SD. Effect of organizational climate upon the job performance of instructors' physical education. Pedagogy of physical culture and sports, 2020;24(2):72-76.

https://doi.org/10.15561/26649837.2020.0204

This is an Open Access article distributed under the terms of the Creative Commons Attribution License, which permits unrestricted use, distribution, and reproduction in any medium, provided the original work is properly cited (http://creativecommons.org/licenses/by/4.0/deed.en). 